Original Research Reports

\title{
Even Conservative Voters Want the Environment to Be at the Heart of Post- COVID-19 Economic Reconstruction in the UK
}

\author{
Ben Kenward ${ }^{1}$, Cameron Brick ${ }^{2}$ \\ [1] Centre for Psychological Research, Oxford Brookes University, Oxford, United Kingdom. [2] Department of Psychology, University of Amsterdam, Amsterdam, \\ The Netherlands.
}

Journal of Social and Political Psychology, 2021, Vol. 9(1), 321-333, https://doi.org/10.5964/jspp.6917

Received: 2020-07-21 • Accepted: 2021-06-02 • Published (VoR): 2021-08-03

Handling Editor: Zoe Leviston, Australian National University, Canberra, Australia

Corresponding Author: Ben Kenward, Centre for Psychological Research, Oxford Brookes University, Headington Campus, Oxford, OX3 0BP, UK. E-mail bkenward@brookes.ac.uk

Supplementary Materials: Data, Materials [see Index of Supplementary Materials]

\begin{abstract}
In 2019, the environment began to rival the economy among priority issues for the UK public. The COVID-19 pandemic has the potential to shift this balance in either direction, because the crisis is not only causing serious economic damage but is also highlighting the usefulness of expert warnings. The current work examines the balance between public prioritisation of environment and economy in the light of the COVID-19 pandemic. A nationally representative YouGov sample of 1654 UK adults were presented with two political speeches, either linking COVID-19 to climate and prioritising environment as part of planned economic recovery, or separating the issues and stating that environmental prioritisation is now unaffordable. Most participants (62\%) were positive towards the environmental prioritisation speech, and it was more popular than the other speech (which $36 \%$ were positive towards). The same proportion of Conservative voters $(62 \%)$ were positive towards the environmental prioritisation speech (with $50 \%$ positive towards the other speech). Higher support for the environmental prioritisation speech was associated with more education but not with socioeconomic status. Voting history and socioeconomic status were therefore less predictive of differences in support for the speeches than expected based on previous research. Consistent with these results is the suggestion that environmental concern in the UK is becoming less tied to social identity and more tied to concern for personal well-being. These findings suggest that foregrounding environmental concerns is politically realistic in post-COVID-19 economic policy, consistent with suggestions from economists and environmental scientists that an environmental focus is feasible and necessary.
\end{abstract}

\section{Keywords}

UK, public opinion, politics, education, socioeconomic status, COVID-19, environment, climate change

\section{Non-Technical Summary}

\section{Background}

The COVID pandemic might have made people less willing to economically prioritise the environment, if the pandemic overshadowed environmental concerns, or more willing, if the pandemic underlined the importance of properly dealing with major societal threats. 


\section{Why was this study done?}

Experts on climate and the economy recommend that attempts to kick-start pandemic-damaged economies must also prioritise the environment, to avert further crises which could dwarf the pandemic in scale. The researchers wanted to find out to what extent the UK public agree, and to find out what demographic factors make a difference.

\section{What did the researchers do and find out?}

A nationally representative sample of the UK population was surveyed and it was found that $62 \%$ are positive to seeing the environment at the heart of post-COVID economic recovery. Furthermore, this number is also $62 \%$ when focusing on Conservative voters, and differences due to social class were insignificant. That the whole population is positive is a confirmation of what we know from other similar polls, but that this applies across demographics is new and unusual. Normally concern about the environment is appreciably more prominent in the middle classes. It seems there may be something about COVID that is making environmental concern more universal. We can't yet be sure what that is but possibly the experience of a new kind of global emergency makes other coming emergencies seem more real to more people.

\section{What do these findings mean?}

These findings mean that in the UK, foregrounding environmental concerns in post-COVID-19 economic policy is not only necessary but politically realistic.

National and personal economic costs are salient impacts of COVID-19. In the United Kingdom (UK), government spending is expected to increase by $10 \%$ of Gross Domestic Product (GDP) for the first affected financial year, but in the most affected quarter GDP is expected to fall by $35 \%$ and unemployment to double (Her Majesty's Treasury, 2020b; Office for Budget Responsibility, 2020). In addition to increased unemployment, 7.5 million workers have been furloughed on $80 \%$ of pay (Her Majesty's Treasury, 2020a). The amount of UK residents with high anxiety has more than doubled to half of the population (Vassilev \& Hamilton, 2020). Although anxiety is affected by more than just economic concerns, household finances rank third on individuals' lists of COVID-19-related concerns, only below mental well-being and work, and well above personal health (Vassilev \& Hamilton, 2020).

The environmental crisis has also recently become more salient to politicians and individuals in the UK. In 2019, the UK parliament declared a Climate Emergency (Hansard House of Commons Debate, 2019). In early 2020 before the pandemic, when naming the three most important issues facing the country, $32 \%$ of UK adults mentioned the environment, compared to $23 \%$ who mentioned the economy (YouGov, 2020). In early 2018, the equivalent figures had been $10 \%$ and $28 \%$ respectively, representing a meaningful shift in the balance between these two concerns (ibid.; see also Ipsos-MORI, 2019). The reasons for this shift are complex but presumably relate in part to high-profile international scientific reports highlighting the severe risks associated with ecosystem degradation and climate change (IPBES, 2019; IPCC, 2018).

The three issues of environment, economy, and COVID-19 intersect in complex ways in both reality and in public perception. The public tends to believe that efforts to preserve the environment come at the cost of the economy (Baker et al., 2017). However, scientific experts have explained that economic activity is itself heavily affected by environmental crises, and thus this zero-sum perception is inaccurate (IPBES, 2019; IPCC, 2018). Further, economists have argued that environmental prioritisation can provide economic benefits, which may be particularly tangible in the context of COVID-19, for example because installation of renewable energy infrastructure provides employment (Hepburn, O'Callaghan, Stern, Stiglitz, \& Zenghelis, 2020). Related arguments have been made by the UK government's own advisors on climate change (Lord Deben \& Baroness Brown of Cambridge, 2020) and by at least two UK government ministers (Sharma, cited in Harrabin, 2020; Raab, 2020). Further, the environmental and COVID-19 emergencies are both scientifically complex problems which have led scientific experts to recommend heavy government intervention into public life. This common aspect might be relevant for how politicians and the public respond to these emergencies. 


\section{Motivation for the Current Study}

Data on public opinion would not only help reveal the mechanisms of opinion formation, but would also give political actors practical information as to the political feasibility of following expert advice related to the environment while undertaking COVID-19-related economic restructuring. The aim of the current research is therefore to provide such data. We aim firstly to describe how the UK population as a whole responds to political arguments about economy and environment in the context of COVID-19, and secondly to examine demographic factors and prior political opinion as predictors of these responses. As yet, there is little investigation of public opinion on the environment in the context of COVID-19 and its economic impact (but see discussion section for further relevant work).

Our method is to examine responses of a nationally representative sample to realistic short political speeches about the place of the environment in post-COVID-19 economic reconstruction. We randomised participants to view either a speech emphasising that environmental prioritisation is now unaffordable as part of post-COVID-19 economic reconstruction because of economic damage, or a speech emphasising that environmental prioritisation is necessary as part of a prosperous economy. Our analytical approach is to make predictions about how support for the environmental prioritisation speech relative to the environment unaffordable speech will depend on individual factors, which we base on pre-COVID-19 data and theory. We then intend to interpret results that deviate from our predictions as indications of how the current context of COVID-19 is influencing opinion. We focus on three main factors previously established as important: socioeconomic status, education level, and political attitudes.

\section{Socioeconomic Status and Environmental Concern}

Although the international picture is very complex (Benegal \& Scruggs, 2016; Mayer \& Smith, 2017; Pampel, 2014; VanHeuvelen \& Summers, 2019), a wide body of evidence indicates that in advanced industrial nations, higher individual socio-economic status (SES) tends to be associated with more concern for the environment (Pampel, 2014). (This broad statement is not intended to diminish the important environmental work done by some disadvantaged communities in these countries, e.g. Bullard, 1983). In wealthier countries, SES tends to be associated with environmental concern because environmental issues less directly impact health and personal finances, and affluent individuals can afford to care about issues that don't immediately impact their well-being. On the other hand, poor individuals in poorer countries are more directly affected by environmental problems, but affluent individuals in poor countries can pay to avoid the problems, leading to weak relations between SES and environmental concern (Pampel, 2014).

It is common in UK datasets to use social grade as an indicator for SES with the standard six-level classification system (from highest to lowest: A, B, C1, C2, D, E) based on employment status and type. For example: A includes high managerial, administrative or professional posts; C1 supervisory, clerical and junior managerial, administrative or professional posts; C2 skilled manual workers; and E casual workers and the unemployed (see Ipsos MediaCT, 2009 for further details). In the UK, higher SES has been frequently associated with more environmental concern; for example, in a government data set from 2010, individuals from the highest social grade were more than twice as likely to be classed as pro-environmental than individuals from the lowest social grade (Rhead, Elliot, \& Upham, 2018). More recently, government data on public opinion is available from mid-March 2020, immediately before the COVID-19 lockdown began to directly impact public life (Department for Business, Energy \& Industrial Strategy, 2020). Amongst the highest two social grades $(n=352), 46 \%$ were very concerned about climate change, whereas amongst the lowest two $(n=569)$, only $24 \%$ were very concerned (Department for Business, Energy \& Industrial Strategy, 2020, cross-tabulation Table 52). Especially as COVID-19 is likely to exacerbate social inequalities (Chinn, Klier, Stern, \& Tesfu, 2020), we predict higher SES (indicated by social grade) will be strongly associated with higher relative support for the environmental prioritisation speech in the current study.

\section{Political Opinion and Environmental Concern}

Individuals with conservative political preferences typically prioritise the environment less, for two distinct reasons. Especially in Anglophone countries, increased political polarisation is associated with an increase in social identification with political groupings, and the conservative social identity now incorporates scepticism towards the importance of 
climate change and environment as an in-group identifier (Driscoll, 2019; Smith \& Mayer, 2019). These social-identity related processes of opinion formation can be in large part independent of specific argument content (Tesler, 2018). The second explanation for conservatives deprioritising the environment is based on specific arguments, however. Environmentalists are perceived as supporting intrusive regulations (Layzer, 2012) that are perceived as economically damaging (Baker et al., 2017), and both intrusive regulations and economic harms conflict with conservative values.

In the UK, recent data confirms that voters for the Conservative party (the mainstream right-wing party, currently in government) are less concerned about the environment compared to other voters. For example, nationally representative data from 2016 showed that $65 \%$ of Conservative voters were worried about climate change, compared to $70 \%$ of all adults (Fisher, Fitzgerald, \& Poortinga, 2018). In late 2019, 57\% of Conservative voters believed that the government's target date for net zero greenhouse gas emissions was too late, compared to $64 \%$ of all adults, and similar survey results were shown in 2019 (Britain Thinks, 2019). Although these effects are modest, we predict that relative support for the environmental prioritisation speech will be lower amongst Conservative voters in this study. The effect may be more pronounced in the context of this study because the speech that deprioritises the environment specifically claims that environmental prioritisation is unaffordable.

\section{Education and Environmental Concern}

More education is consistently correlated with increased concern for the environment (Meyer, 2015). The reasons for this could include social-identity related processes as outlined above. However, greater knowledge of the scientific consensus around climate change uniquely predicts greater concern about climate change, even when accounting for a range of socio-cultural factors in the UK (van der Linden, 2015). More education is also related to environmental concern in recent nationally representative UK samples (e.g. Britain Thinks, 2019). Therefore, we predict that more education will be associated with stronger relative support for the environmental prioritisation speech in this study.

The association between education and environmental concern is moderated by political opinion, at least in US samples. For political conservatives, the association is weaker or even negative, because of the different information sources and norms that circulate in different political communities (Hamilton, 2011; McCright, 2011). We therefore also predict that the effects of education on relative speech support will be weaker for Conservative voters.

\section{Method}

YouGov surveyed a sample of 1654 UK (without Northern Ireland) adults between $30^{\text {th }}$ April and $1^{\text {st }}$ May 2020 using an active sampling procedure that approximately balanced the sample to nationally representative quotas for age, gender, social grade, education level, region, political attention, and 2019 General Election and 2016 EU Referendum votes. YouGov further calculated a weight variable using the above variables to match the sample to national population records. Weighting was not excessive (10\% and $90 \%$ quantiles for the weight variable were 0.58 and 1.52 respectively) indicating adequate quota balance. The anonymous data was commissioned from YouGov by the Extinction Rebellion, an environmental campaigning organisation, and released publicly at https:/osf.io/8edf3/.

In a between-subjects design, participants were instructed to read one randomly selected speech and then respond to three questions in randomised order, with responses on 7-point Likert scales:

- "Based on this speech, how likely would you be to vote for this politician?" Response options: Very unlikely (coded 1); Unlikely; Somewhat unlikely; Neither likely nor unlikely; Somewhat likely; Likely; Very likely (coded 7).

- "Are the values displayed in this speech similar or different to your own values?" Response options: Very different (coded 1); Different; Somewhat different; Neither similar nor different; Somewhat similar, Similar, Very similar (coded 7).

- "Do you agree or disagree that the arguments in this speech make good sense?" Response options: Strongly disagree (coded 1); Disagree; Somewhat disagree; Neither agree nor disagree; Somewhat agree; Agree; Strongly agree (coded 7).

The speeches were balanced for total number of words (138) and the occurrence numbers of the following key phrases: act, climate change, COVID-19, economy, pandemic, prosperous economy, threat, warnings from experts. To improve 
the ecological validity of the speeches, a UK Member of Parliament and a UK national TV news editor were consulted on draft versions. The chief difference between the speeches was an emphasis that environmental prioritisation is now unaffordable because of economic damage, versus an emphasis that environmental prioritisation is necessary as part of a prosperous economy. The speeches additionally differed in emphasising the different nature of the COVID-19 and climate threats, versus emphasising their similarity in terms of requirements to actively respond to expert warnings. The design choice deliberately sacrificed the possibility to distinguish potential effects of these two varying aspects in favour of ecological validity: most political speeches would conflate these aspects. Each speech began with the same preamble intended to provide a politically realistic context:

Thanks to the sacrifices of doctors, nurses, other key workers, and everyone doing their bit by staying at home, we may soon have passed the peak of the COVID-19 pandemic. The time will then come to repair the very serious damage to our economy. As we do so, there will be those who call for the environment to be a key focus as the economy is rebuilt. [Continues with one of the two sections below.]

Environment unaffordable:

However, we must not be distracted by attempts to link COVID-19 and climate change. Warnings from experts should not be ignored, but these two threats are different and each requires us to act differently. The pandemic has caused so much damage to our economy that we can't currently afford to focus on the environment. Only with a prosperous economy will we later be able to resume our focus on climate change.

Environment prioritised:

And indeed, we must learn the lesson that we ignore warnings from experts at our peril, with regard to pandemics or climate change. COVID-19 is a wake-up call, but one that shows we can act. The environment must therefore be at the heart of our future economy, as we rebuild a society prepared to tackle catastrophic climate change. Only if we also address this threat will a prosperous economy be sustainable.

Education was calculated by collapsing 20 provided categories to six ordinal levels: No formal qualifications (scored as 1); GCSE (primarily exam-based qualifications typically taken at age 16) or equivalent; A-level (similar to GCSE but typically taken at age 18) or equivalent; tertiary education not conferring a university degree; first university degree; higher university degree (scored as 6). Social grade was indicated in the six ordinal categories used in the UK (A, B, C1, C2, D, and E) with the highest grade (A) scored 6. For each of Education and Social grade, to enable dichotomous analyses the first three and second three categories were further grouped. As a proxy for right-wing political attitudes, a dichotomous variable Conservative vote was created: voted Conservative in the 2019 general election (1) or did not (0).

All statistical and graphical analyses were conducted in R (R Core Team, 2019) and were weighted with the YouGov-provided weighting variable. $\mathrm{R}$ code which replicates the analyses is available at https://osf.io/945wg/. The models were constructed with the svyglm function (Lumley, 2010) with default parameters, which implements a linear regression model of standard type (except for the weighting; see R code). Alpha was set at .05 for confirmatory tests. Hypotheses for the effects of each predictor variable on relative speech support (operationalised as interactions with Speech condition) were created prior to analysis.

\section{Results}

Responses to the three questions were very strongly correlated (Spearman's $r$ between .73 and .80 , Cronbach's $\alpha=.92$ ), so they were combined into a mean composite (called Support) and transformed by subtracting 4 so that 0 represents neutrality and the limits are -3 (full opposition) to 3 (full support). Support was modelled using weighted linear 
regression as a function of the variables shown in Table $1\left(R_{\text {adjusted }}^{2}=.17\right)$. Education and Social grade were entered as centred scale variables.

All research questions regard the Speech condition and its interactions, because a variable's interaction with Speech measures how that variable is associated with differences in Support for the two speeches. All other main effects relate to different Support levels irrespective of Speech condition, and therefore do not inform the research questions. These main effects are included in the model to control for differences in Support independent of Speech condition (and revealed that less educated people and Conservative voters give higher Support irrespective of which speech they viewed, Table 1).

Participants gave more Support to the environment prioritised (main effect of Speech, Table 1). Interactions with Speech were detected for Education and Conservative vote, but not Social grade, Age, or Gender. These interactions indicate the following. Each 1-point increase in Education (6-point scale) was associated with 0.29 points, 95\% CI $[0.17,0.41]$, more Support (7-point scale) for the environment prioritised speech compared to the environment unaffordable speech. However, higher Support is given to the environment prioritised speech even by those without tertiary education (Figure 1, left panels; $t(837)=4.70, p<.001$, Mood's median test). Support was higher for the environment prioritised speech even when focusing on the subset of Conservative voters (Figure 1, lower panels; $t(599)=2.05$, $p=.041$, Mood's median test). This difference in Support was, however, 0.90 points smaller, $95 \%$ CI $[0.51,1.30]$ in Conservative voters compared to the rest of the population.

The significant three-way interaction between Speech, Vote, and Education (Table 1) suggested that the combined effects of Education and not voting Conservative were more than just additive (Figure 1). Although increased Education and not voting Conservative each have moderate effects, together the effects are stronger (Figure 1; top right panel). The regression coefficient indicates that for each additional point of education, Conservative voters compared to others displayed a 0.28 point, $95 \%$ CI $[0.10,0.47]$ lower increase in the extent to which the environment prioritised speech was more strongly supported. Given that this figure is 0.29 in the whole population (Education by Speech interaction coefficient), this indicates that for Conservative voters, unlike for others, education is not associated with relative support for the speeches (Figure 1; bottom panels).

Table 1

Linear Regression Model of Speech Support

\begin{tabular}{|c|c|c|c|c|}
\hline Model term & $\boldsymbol{b}$ & $S E$ & $t$ & $p$ \\
\hline Intercept & -0.53 & 0.11 & -5.04 & $<.001$ \\
\hline Speech condition $($ environment prioritisation $=1)$ & 0.99 & 0.13 & 7.66 & $<.001$ \\
\hline Conservative vote $($ yes $=1)$ & 0.74 & 0.18 & 4.13 & $<.001$ \\
\hline Age (years) & 0.01 & 0.00 & 1.09 & .276 \\
\hline Gender $($ female $=1)$ & 0.04 & 0.13 & 0.32 & .748 \\
\hline Social grade (1-6) & -0.04 & 0.04 & -0.95 & .340 \\
\hline Education (1-6) & -0.12 & 0.05 & -2.38 & .017 \\
\hline Speech $\mathrm{x}$ Conservative vote & -0.90 & 0.20 & -4.48 & $<.001$ \\
\hline Speech x Age & 0.00 & 0.01 & -0.70 & .486 \\
\hline Speech x Gender & 0.29 & 0.16 & 1.88 & .060 \\
\hline Speech x Social grade & 0.09 & 0.05 & 1.80 & .072 \\
\hline Speech x Education & 0.29 & 0.06 & 4.65 & $<.001$ \\
\hline Conservative vote $\mathrm{x}$ Education & 0.09 & 0.07 & 1.20 & .229 \\
\hline Speech $\mathrm{x}$ Conservative vote $\mathrm{x}$ Education & -0.28 & 0.10 & -2.97 & .003 \\
\hline
\end{tabular}

Note. For dichotomous variables, the alternative not mentioned above was coded as 0 (Speech: environment unaffordable; Conservative vote: no; Gender: male). Parameters for model terms significant at alpha $=.05$ are shown in bold. 


\section{Figure 1}

Frequency Density Plots for Support, by Education and Conservative Vote

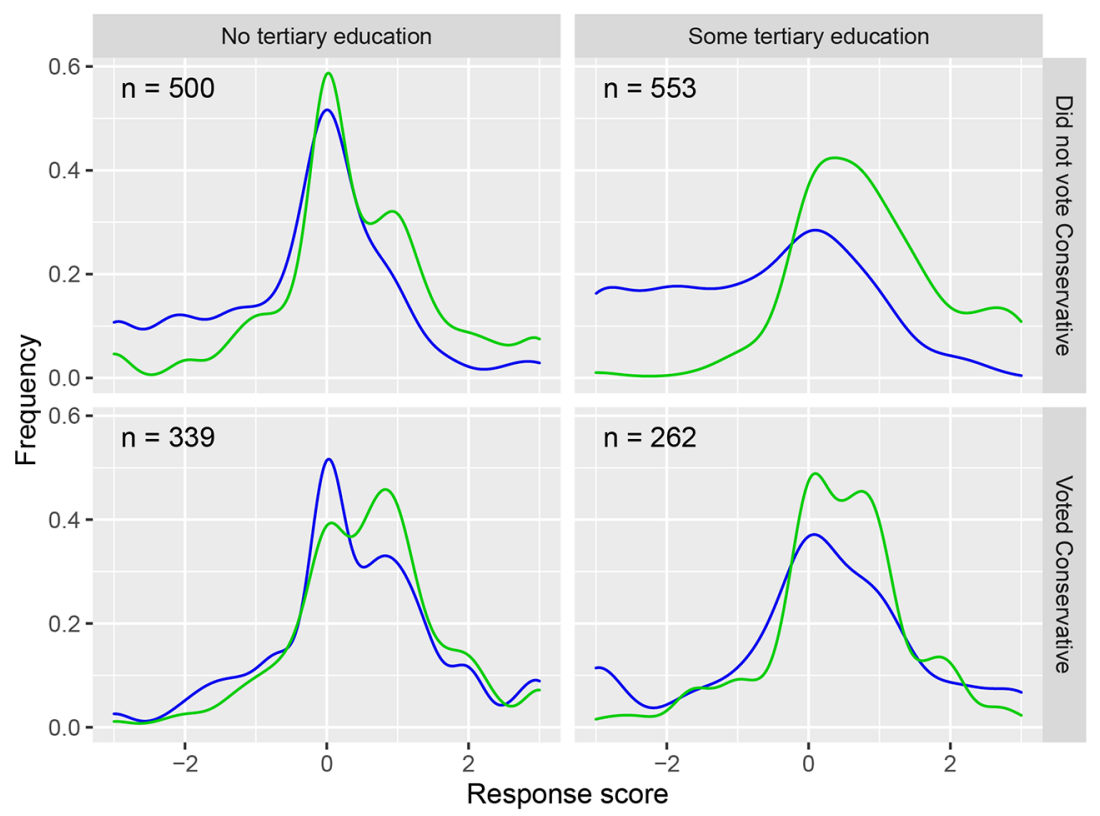

Speech: Environment unaffordable $\square$ Speech: Environment prioritised

Note. Kernel density calculated using the default parameters of the geom_density R function.

Inspection of the diagnostic residual plots ( $\mathrm{Q}-\mathrm{Q}$ and residuals versus fitted values) revealed adequate model fit except the residual distribution had somewhat heavy tails. To test for robustness, the data was therefore also modelled using binary logistic regression by collapsing Support to a dichotomous variable (positive or negative). The results were substantively the same (see Supplementary Materials for details).

Collapsing Support to positive $(>0)$, negative $(<0)$, or neutral $(=0)$ responses allows simple and informative visualisations (Figure 2), showing that $62 \%$ of participants are positive to the environment prioritised speech, whether or not Conservative voters. However, although $41 \%$ of all voters are negative towards the environment unaffordable speech, this figure was only $26 \%$ in Conservative voters.

Because of the unexpected failure to detect an effect of Social grade on relative Support for the speeches (no interaction between Speech and Social grade), we provide responses to the environment prioritised speech broken down by social grade, in a form suitable for comparison with the above-mentioned recent UK government figures. Of the two highest social grades, A and B, 65\%, 95\% CI [59\%, 70\%] gave a positive response to the environment prioritised speech, whereas it was $59 \%, 95 \%$ CI [50\%, 67\%] for the two lowest social grades, D and E. The Speech by Social grade interaction regression coefficient $95 \% \mathrm{CI}$ of $[-0.01,0.18]$ suggests that any undetected effect is unlikely to represent more than a 0.90 point difference in relative Support between the lowest and highest social grades $(0.90=95 \%$ CI upper limit of 0.18 * 5 steps between grades). 
Figure 2

Percentages $\pm 95 \%$ Confidence Intervals for Negative ( $<0)$, Positive $(>0)$, or Neutral $(=0)$ Speech Responses, Showing (a) UK Population, and (b) Conservative Voters Only

(a) UK population $(\mathrm{n}=1654)$

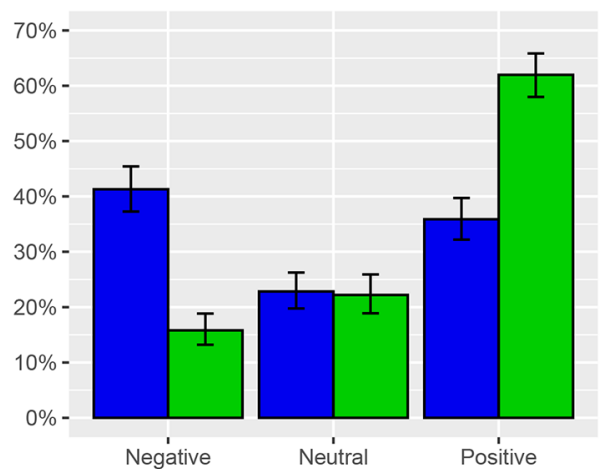

Speech: Environment unaffordable (b) Conservative voters only $(\mathrm{n}=601)$

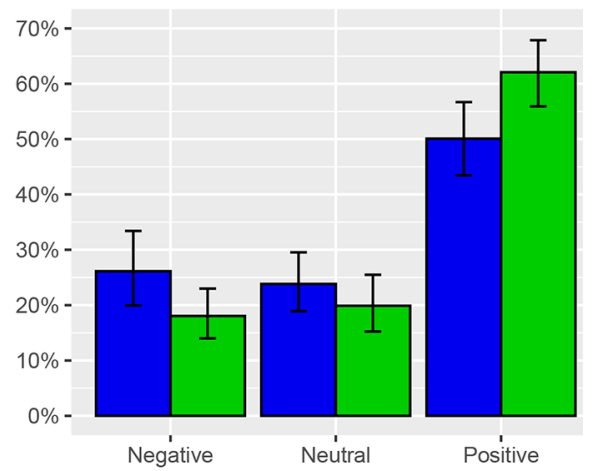

Speech: Environment prioritised

\section{Discussion}

This work aimed to explore the UK public's support for different political speeches concerning the economy and the environment in the context of COVID-19, and to test predictions that greater support for environmental prioritisation would be positively associated with education, social grade, and not voting Conservative, but with the effects of education attenuated in Conservative voters. The UK public gave stronger support to a speech arguing for environmental prioritisation as part of post-COVID-19 economic recovery measures, in comparison to a speech arguing that environmental prioritisation is now unaffordable because of COVID-19 related economic damage. This held across all investigated subsamples based on demographics and political affiliation. In fact, despite our predictions based on (amongst other sources) UK data collected immediately prior to COVID-19 lockdown, social grade had no detected effect on relative speech support, with confidence intervals suggesting that any undetected effect was probably modest.

Although we did observe the predicted effects whereby Conservative voters and the less educated showed a lower tendency to give more support to the environment prioritised speech, these moderation effects were modest. When examining positive versus negative or neutral ratings of the environment prioritised speech, for example, $62 \%$ of Conservative voters were positive, the same as in the whole sample. These results are surprising given that apart from health-related issues, at the time of data collection the UK national discourse concerning COVID-19 was dominated by discussion of economic impact. ${ }^{1}$

Because of the goal of measuring opinion in the explicitly mentioned context of COVID-19, our results are not directly comparable with pre-COVID-19 measures of environmental concern. This is not to say compatible measures are no longer possible (for example the UK Government could re-implement its regular polling of opinion on energy and climate change which was suspended due to COVID-19 lock-down; Department for Business, Energy \& Industrial Strategy, 2020). However, these results indicate that COVID-19 has not reduced public desire to prioritise the environment. Further, this conclusion is now supported by converging evidence. A comprehensive international poll conducted in mid-April 2020 (Ipsos Global Advisor, 2020) found the following with respect to its nationally representative UK sample. Most people (66\%) agreed that climate change is as serious a crisis as COVID-19. Most people (58\%) agreed that government actions should prioritize climate change in the economic recovery after COVID-19 (note the close match with our $62 \%$ positive to environmental prioritisation). However, also reflecting our results, a substantial minority (46\%)

1) Factiva searches for UK newspaper content between $23^{\text {rd }}$ March 2020 (the date of UK lock-down) and $14^{\text {th }}$ May 2020 revealed 4513 hits for "(economy or unemployment) and covid" and 1269 hits for "(environment or climate change) and covid", a ratio of 3.6 to 1. 
did agree that the environment should sometimes be sacrificed for the sake of the economy. A further UK opinion poll conducted in April (Stone, 2020) found that 48\% agreed that the government should respond "with the same urgency to climate change as it has with COVID-19", with $28 \%$ disagreeing. Even more recent surveys from the UK and USA suggest that although there is some evidence for a finite pool of worry, increases in concern about COVID-19 have not been accompanied by correspondingly large decreases in environmental concern (Bostrom, Böhm, Hayes, \& O'Connor, 2020; Evensen et al., 2021).

Due to logistic constraints, it was not possible to measure further psychological variables that would have properly clarified the psychological processes that lead to the opinions measured here (Pearson, Schuldt, \& Romero-Canyas, 2016; van der Linden, 2015). However, some conclusions about processes governing opinions are possible. More educated individuals prefer environmental prioritisation, which can be explained with reference to studies showing the importance of accurate knowledge of climate change processes for motivating concern (Shi, Visschers, Siegrist, \& Arvai, 2016; van der Linden, 2015).

Conservative voters' somewhat reduced tendency to give more support to the environment prioritised speech compared to other voters was likely because of different political priorities (Baker et al., 2017; Layzer, 2012). We further observed that, in line with our prediction, additional education in Conservative voters did not increase relative support for environmental prioritisation, unlike in the rest of the population. This result suggests a role for social identity related processes by which some Conservatives are subject to knowledge resistance (Klintman, 2019), therefore developing opinions in line with perceived norms for their social group (Driscoll, 2019; Hamilton, 2011; McCright, 2011; Smith \& Mayer, 2019; Tesler, 2018). Individual perceptions of what is believed by others within a social group do not necessarily reflect what others actually believe, however; and an important part of within-group opinion change is when individuals become informed that their perceptions of group opinion are out of date (Bicchieri, 2006, 2016; Van Boven, Ehret, \& Sherman, 2018). Given that some Conservatives may be surprised that the majority of Conservatives are positive towards environmental prioritisation in post-COVID-19 economic reconstruction, publication of this result could be expected to further increase support.

The finding that social grade was not related to relative support for the different speeches was the most surprising, given previous strong effects of social grade on environmental concern in the UK (Department for Business, Energy \& Industrial Strategy, 2020; Rhead et al., 2018) and in some other similar countries (Pampel, 2014). While a conclusive explanation requires further work, potential explanations are available. Low-SES individuals in developed countries typically place a lower priority on environmental policies because they anticipate personal costs and benefits they can do without (Baker et al., 2017; Benegal \& Scruggs, 2016; Pampel, 2014). During 2019, prompted by high-profile scientific reports (IPBES, 2019; IPCC, 2018), the UK national discourse was at times dominated by discussion of environmental issues, ${ }^{2}$ with the climate and ecological emergencies often presented as directly threatening to individuals in the UK. Although this was not in itself enough to remove the association between SES and environmental concern, which was present in 2020 immediately before the pandemic (Department for Business, Energy \& Industrial Strategy, 2020), there are numerous reasons why the context of COVID-19 might have prompted reappraisal by low-SES individuals of their anticipated personal impact, leading to the current result. Trust in experts may have increased; belief in the possibility of major social disturbance may have increased; national solidarity may have increased; etc. These possibilities are ripe for further investigation, but in short, it appears likely that concern for personal well-being is becoming more closely tied to environmental concerns, and less closely tied to purely economic concerns. In line with this suggestion, a UK YouGov poll in May 2020 asked participants to choose between "more economic growth" and "improved social and environmental outcomes" for post-COVID-19 national priorities; only 31\% chose economic growth, and $61 \%$ chose social and environmental outcomes (Youel, 2020).

Generalisation of the current findings to different populations or to superficially similar political speeches should be undertaken only with great caution. In countries such as the USA or Australia, where political polarisation over the environment is even stronger than in the UK (Colvin \& Jotzo, 2021; Hornsey, Harris, \& Fielding, 2018), the environmental prioritisation speech might be rated less well, particular amongst conservatives.

2) Factiva searches for UK newspaper content containing "climate change" revealed 17956 hits for 2019 compared to 8917 hits for 2018 , an increase of $101 \%$. 
Regarding the speeches, it is noteworthy that both emphasised the importance of the economy; the key difference in this regard was that one speech argued that COVID-19 made environmental measures unaffordable, whereas one speech emphasised that environmental measures are necessary for a sustainable economic recovery. This design decision was taken to increase the relevance of the results to the mainstream political arena, in which arguments explicitly discounting the economy are seldom made. We speculate that without this component, the environment prioritised speech would have been less successful, and the small differences found between Conservative and non-Conservative voters would have been larger. Indeed, an argument that the environment must take second place to the economy because of COVID-19 has been found to reduce support for costly environmental measures (Ecker et al., 2020).

In addition to the different ways in which the speeches related COVID-19 to the economy, they also differed in how they related COVID-19 to the environment (as a wake-up call or as disconnected). Ecker et al. (2020) found that a similar wake-up call argument was ineffective in increasing pro-environmental sentiment. This might suggest that the most powerful aspect of the speech was the argument that only if post-COVID-19 economic recovery addresses the climate will it be truly sustainable. However, we also note that Ecker et al. tested individuals in the US, and they may relate differently to this argument.

Other contextual factors should also be born in mind when considering the results. Firstly, because of the political context of Brexit, a vote for the Conservatives in the 2019 UK general election was a less clear-cut indication of support for conservative ideology than previously (Curtice, 2019). This could perhaps in part explain the smaller than expected differences between Conservative and non-Conservative voters and therefore reflects an important limitation of the study. Secondly, by restricting their ordinary indoor activities, COVID-19 had the effect of increasing people's awareness of nature, which may have influenced their support for environmental measures (Rousseau \& Deschacht, 2020; Severo, De Guimarães, \& Dellarmelin, 2021).

In conclusion, these results and other recent surveys suggest that the public is still hungry for measures to address environmental crises such as climate change, even during COVID-19. Environmental concern remains high and is less contingent on political affiliation and SES than in the past. There remains a substantial minority who believe the environment should rank second to the economy in the current context. Nonetheless, these observations underline the political feasibility of following expert advice to foreground the environment in post-COVID-19 economic reconstruction (Hepburn et al., 2020). Despite this, most governments, including that of the UK, have not evidenced strong prioritisation of the environment in post-COVID-19 reconstruction so far. The corporate analyst Bloomberg (2020) calculates that only $0.2 \%$ of post-COVID government stimulus in the 50 largest economies has been targeted at the environment. In the UK, the Bank of England has supported four airlines and three carmakers with lending totalling more than $£ 3$ billion under the COVID Corporate Financing Facility scheme (Bank of England, 2020). It is therefore urgent to inform policy makers that experts and the public agree that the environment should be prioritised.

Funding: The authors have no funding to report.

Acknowledgments: The authors thank in particular Stuart Capstick, Ben Farrer, Bahar Tuncgenc, Marijn Meijers, and Mark Burgess for comments on the method and the manuscript; and also thank Christine Fawcett, Wakefield Morys-Carter, Kahl Hellmer, Adam Baimel, Adam Corner, and Bridget Kenward for further assistance.

Competing Interests: Ben Kenward participated in study design through a role within the Extinction Rebellion. Cameron Brick served as an independent scientist (not a member of the organization) and joined the project during data analysis.

Data Availability: For this article, a dataset is freely available (Kenward, 2020a).

\section{Supplementary Materials}

The Supplementary Materials contain the following items (for access see Index of Supplementary Materials below):

- Raw data

- Analysis code in $\mathrm{R}$ 
- Supplementary analysis confirming robustness

\section{Index of Supplementary Materials}

Kenward, B. (2020a). Public opinion on environmental prioritisation in post-COVID-19 economic reconstruction [Research data commissioned from YouGov by Extinction Rebellion]. OSF. https://osf.io/8edf3/

Kenward, B. (2020b). R code for: Even Conservative voters prefer the environment to be at the heart of post-COVID-19 economic reconstruction in the UK [Code]. OSF. https://osf.io/945wg/

Kenward, B., \& Brick, C. (2021c). Supplementary materials to "Even conservative voters want the environment to be at the heart of postCOVID-19 economic reconstruction in the UK" [Additional analyses]. PsychOpen GOLD. https://doi.org/10.23668/psycharchives.5013

\section{References}

Baker, S., Craig, R. K., Hirokawa, K., Krakoff, S., Owley, J., Powers, M., . . Takacs, D. (2017). Beyond zero-sum environmentalism. Environmental Law Reporter, 47(4), Article 10328.

Bank of England. (2020). Businesses with outstanding CP held by the CCFF, and nominal value, at 15 July 2020. Bank of England. Retrieved from

https://www.bankofengland.co.uk/-/media/boe/files/markets/covid-corporate-financing-facility/cp-held-by-ccff-by-business.xlsx

Benegal, S., \& Scruggs, L. (2016). Economic conditions and public opinion on climate change. In Oxford Research Encyclopedia of Climate Science. Retrieved from https://oxfordre.com/climatescience/view/10.1093/acrefore/9780190228620.001.0001/acrefore-9780190228620-e-310

Bicchieri, C. (2006). The grammar of society: The nature and dynamics of social norms. New York, NY, USA: Cambridge University Press.

Bicchieri, C. (2016). Norms in the wild: How to diagnose, measure, and change social norms. Oxford, United Kingdom: Oxford University Press.

Bloomberg. (2020, June 9). How to grow green: 26 ways to launch a clean energy future out of the pandemic recovery. Bloomberg. Retrieved from https://www.bloomberg.com/features/2020-green-stimulus-clean-energy-future/

Bostrom, A., Böhm, G., Hayes, A. L., \& O’Connor, R. E. (2020). Credible threat: Perceptions of pandemic coronavirus, climate change and the morality and management of global risks. Frontiers in Psychology, 11, Article 578562. https://doi.org/10.3389/fpsyg.2020.578562

Britain Thinks. (2019). Engage Britain: Challenges facing Britain survey. Britain Thinks. Retrieved from https://britainthinks.com/pdfs/Engage_Britain_2019_Data-Tables.pdf

Bullard, R. D. (Ed.). (1983). Confronting environmental racism: Voices from the grassroots. Boston, MA, USA: South End Press.

Chinn, D., Klier, J., Stern, S., \& Tesfu, S. (2020). Safeguarding Europe's livelihoods: Mitigating the employment impact of COVID-19. McKinsey \& Company. Retrieved from https://www.mckinsey.com/industries/public-sector/our-insights/safeguarding-europes-livelihoods-mitigating-the-employmentimpact-of-covid-19

Colvin, R. M., \& Jotzo, F. (2021). Australian voters' attitudes to climate action and their social-political determinants. PLoS One, 16(3), Article e0248268. https://doi.org/10.1371/journal.pone.0248268

Curtice, J. (2019). 2019 election - Brexit reshapes party support. UK in a changing Europe. Retrieved from https://ukandeu.ac.uk/2019-election-brexit-reshapes-party-support/

Department for Business, Energy \& Industrial Strategy. (2020). BEIS Public Attitudes Tracker: Wave 33. BEIS. Retrieved from https://www.gov.uk/government/statistics/beis-public-attitudes-tracker-wave-33

Driscoll, D. (2019). Assessing sociodemographic predictors of climate change concern, 1994-2016. Social Science Quarterly, 100(5), 1699-1708. https://doi.org/10.1111/ssqu.12683

Ecker, U. K. H., Butler, L. H., Cook, J., Hurlstone, M. J., Kurz, T., \& Lewandowsky, S. (2020). Using the COVID-19 economic crisis to frame climate change as a secondary issue reduces mitigation support. fournal of Environmental Psychology, 70, Article 101464. https://doi.org/10.1016/j.jenvp.2020.101464 
Evensen, D., Whitmarsh, L., Bartie, P., Devine-Wright, P., Dickie, J., Varley, A., . . Mayer, A. (2021). Effect of "finite pool of worry" and COVID-19 on UK climate change perceptions. Proceedings of the National Academy of Sciences of the United States of America, 118(3), Article e2018936118. https://doi.org/10.1073/pnas.2018936118

Fisher, S., Fitzgerald, R., \& Poortinga, W. (2018). Climate change: Social divisions in beliefs and behaviour. In D. Phillips, J. Curtice, M. Phillips, \& J. Perry (Eds.), British Social Attitudes: The 35th Report (pp. 146-171). London, United Kingdom: The National Centre for Social Research.

Hamilton, L. C. (2011). Education, politics and opinions about climate change evidence for interaction effects. Climatic Change, 104(2), 231-242. https://doi.org/10.1007/s10584-010-9957-8

Hansard House of Commons Debate. (2019). vol. 659 cols. 226-309, 01 May 2019. Hansard. Retrieved from https://hansard.parliament.uk/Commons/2019-05-01/debates/3C133E25-D670-4F2B-B245-33968D0228D2/ EnvironmentAndClimateChange

Harrabin, R. (2020, April 25). Coronavirus recovery plan 'must tackle climate change'. BBC. https://www.bbc.co.uk/news/science-environment-52418624

Hepburn, C., O'Callaghan, B., Stern, N., Stiglitz, J., \& Zenghelis, D. (2020). Will COVID-19 fiscal recovery packages accelerate or retard progress on climate change? (Oxford Smith School of Enterprise and the Environment | Working Paper No. 20-02). Retrieved from https://www.smithschool.ox.ac.uk/publications/wpapers/workingpaper20-02.pdf

Her Majesty's Treasury. (2020a). Chancellor extends furlough scheme until October. Her Majesty's Treasury. Retrieved from https://www.gov.uk/government/news/chancellor-extends-furlough-scheme-until-october

Her Majesty's Treasury. (2020b). HM Treasury announces revision to the UK Debt Management Office's financing remit 2020-21. Her Majesty's Treasury. Retrieved from

https://www.gov.uk/government/news/hm-treasury-announces-revision-to-the-uk-debt-management-offices-financingremit-2020-21

Hornsey, M. J., Harris, E. A., \& Fielding, K. S. (2018). Relationships among conspiratorial beliefs, conservatism and climate scepticism across nations. Nature Climate Change, 8(7), 614-620. https://doi.org/10.1038/s41558-018-0157-2

IPBES. (2019). Summary for policymakers. In S. Díaz, J. Settele, E. S. Brondízio, H. T. Ngo, M. Guèze, J. Agard, A. Arneth, P. Balvanera, K. A. Brauman, S. H. M. Butchart, K. M. A. Chan, L. A. Garibaldi, K. Ichii, J. Liu, S. M. Subramanian, G. F. Midgley, P. Miloslavich, Z. Molnár, D. Obura, A. Pfaff, S. Polasky, A. Purvis, J. Razzaque, B. Reyers, R. R. Chowdhury, Y. J. Shin, I. J. Visseren-Hamakers, K. J. Willis, \& C. N. Zayas (Eds.), The global assessment report on biodiversity and ecosystem services (pp. 56). Bonn, Germany: IPBES secretariat.

IPCC. (2018). Summary for policymakers. In V. Masson-Delmotte, P. Zhai, H. O. Pörtner, D. Roberts, J. Skea, P. R. Shukla, A. Pirani, W. Moufouma-Okia, C. Péan, R. Pidcock, S. Connors, J. B. R. Matthews, Y. Chen, X. Zhou, M. I. Gomis, E. Lonnoy, T. Maycock, M. Tignor, \& T. Waterfield (Eds.), Global warming of $1.5^{\circ} \mathrm{C}$. An IPCC Special Report on the impacts of global warming of $1.5^{\circ} \mathrm{C}$ above preindustrial levels and related global greenhouse gas emission pathways, in the context of strengthening the global response to the threat of climate change, sustainable development, and efforts to eradicate poverty (p. 32). Geneva, Switzerland: World Meteorological Organization.

Ipsos-MORI. (2019). Brexit remains Britons' top concern whilst worry over the environment hits its highest level since 1990. IpsosMORI. Retrieved from

https://www.ipsos.com/ipsos-mori/en-uk/brexit-remains-britons-top-concern-whilst-worry-over-environment-hits-its-highestlevel-1990

Ipsos Global Advisor. (2020). Earth Day 2020: How do Great Britain and the world view climate change and Covid-19? Ipsos-MORI.

Retrieved from https:/www.ipsos.com/sites/default/files/ct/news/documents/2020-04/earth_day_slide_deck.pdf

Ipsos MediaCT. (2009). Social grade: A classification tool. Ipsos-MORI. Retrieved from

https://www.ipsos.com/sites/default/files/publication/6800-03/MediaCT_thoughtpiece_Social_Grade_July09_V3_WEB.pdf

Klintman, M. (2019). Knowledge resistance: How we avoid insight from others. Manchester, United Kingdom: Manchester University Press.

Layzer, J. A. (2012). Open for business: Conservatives' opposition to environmental regulation. Cambridge, MA, USA: The MIT Press. Lord Deben, \& Baroness Brown of Cambridge. (2020). Building a resilient recovery from the COVID-19 crisis. Climate Change

Committee. Retrieved from 
https://www.theccc.org.uk/publication/letter-building-a-resilient-recovery-from-the-covid-19-crisis-to-prime-minister-borisjohnson/

Lumley, T. (2010). Complex surveys: A guide to analysis using R. Hoboken, NJ, USA: John Wiley and Sons.

Mayer, A., \& Smith, E. K. (2017). Rethinking economic conditions and environmental attitudes: Macroeconomic effects, individual experiences, and subjectivity. Social Currents, 4(4), 342-359. https://doi.org/10.1177/2329496516670185

McCright, A. M. (2011). Political orientation moderates Americans' beliefs and concern about climate change. Climatic Change, 104(2), 243-253. https://doi.org/10.1007/s10584-010-9946-y

Meyer, A. (2015). Does education increase pro-environmental behavior? Evidence from Europe. Ecological Economics, 116, 108-121. https://doi.org/10.1016/j.ecolecon.2015.04.018

Office for Budget Responsibility. (2020). Coronavirus analysis. Office for Budget Responsibility. Retrieved from https://obr.uk/coronavirus-analysis/

Pampel, F. C. (2014). The varied influence of SES on environmental concern. Social Science Quarterly, 95(1), 57-75. https://doi.org/10.1111/ssqu.12045

Pearson, A. R., Schuldt, J. P., \& Romero-Canyas, R. (2016). Social climate science: A new vista for psychological science. Perspectives on Psychological Science, 11(5), 632-650. https://doi.org/10.1177/1745691616639726

R Core Team. (2019). R: A language and environment for statistical computing. Vienna, Austria: R Foundation for Statistical Computing. Raab, D. [Dominic Raab] (2020, April 28). While the world is rightly focused on \#COVID19, challenges of climate change have not gone away [Tweet]. Retrieved from https://twitter.com/DominicRaab/status/1255236963642335232

Rhead, R., Elliot, M., \& Upham, P. (2018). Using latent class analysis to produce a typology of environmental concern in the UK. Social Science Research, 74, 210-222. https://doi.org/10.1016/j.ssresearch.2018.06.001

Rousseau, S., \& Deschacht, N. (2020). Public awareness of nature and the environment during the COVID-19 crisis. Environmental and Resource Economics, 76(4), 1149-1159. https://doi.org/10.1007/s10640-020-00445-w

Severo, E. A., De Guimarães, J. C. F., \& Dellarmelin, M. L. (2021). Impact of the COVID-19 pandemic on environmental awareness, sustainable consumption and social responsibility: Evidence from generations in Brazil and Portugal. fournal of Cleaner Production, 286, Article 124947. https://doi.org/10.1016/j.jclepro.2020.124947

Shi, J., Visschers, V. H. M., Siegrist, M., \& Arvai, J. (2016). Knowledge as a driver of public perceptions about climate change reassessed. Nature Climate Change, 6(8), 759-762. https://doi.org/10.1038/nclimate2997

Smith, E. K., \& Mayer, A. (2019). Anomalous Anglophones? Contours of free market ideology, political polarization, and climate change attitudes in English-speaking countries, Western European and post-Communist states. Climatic Change, 152(1), 17-34. https://doi.org/10.1007/s10584-018-2332-x

Stone, J. (2020, April 16). Public want radical response to climate change with same urgency as coronavirus, poll finds. Independent. Retrieved from

https://www.independent.co.uk/environment/climate-change/coronavirus-climate-crisis-uk-government-poll-environmenta9467371.html

Tesler, M. (2018). Elite domination of public doubts about climate change (not evolution). Political Communication, 35(2), $306-326$. https://doi.org/10.1080/10584609.2017.1380092

Van Boven, L., Ehret, P. J., \& Sherman, D. K. (2018). Psychological barriers to bipartisan public support for climate policy. Perspectives on Psychological Science, 13(4), 492-507. https://doi.org/10.1177/1745691617748966

van der Linden, S. (2015). The social-psychological determinants of climate change risk perceptions: Towards a comprehensive model. fournal of Environmental Psychology, 41, 112-124. https://doi.org/10.1016/j.jenvp.2014.11.012

VanHeuvelen, T., \& Summers, N. (2019). Divergent roads: A cross-national intercohort analysis of affluence and environmental concern. Social Science Research, 82, 72-91. https://doi.org/10.1016/j.ssresearch.2019.04.001

Vassilev, G., \& Hamilton, M. (2020). Personal and economic well-being in Great Britain: May 2020. Office for National Statistics. Retrieved from https://www.ons.gov.uk/peoplepopulationandcommunity/wellbeing/bulletins/personalandeconomicwellbeingintheuk/may2020

Youel, S. (2020). New polling: Only $12 \%$ want uk to prioritise economic growth over wellbeing. Positive Money. Retrieved from https://positivemoney.org/2020/05/new-polling-only-12-want-uk-to-prioritise-economic-growth-over-wellbeing/

YouGov. (2020). YouGov tracker most important issues. YouGov. Retrieved from https://yougov.co.uk/topics/political-trackers/survey-results 